\title{
Reviews
}

\section{Takashi Ito}

\section{Rethinking the Age of Zoo Reform}

Lisa Uddin, Zoo Renewal: White Flight and the Animal Ghetto. Minneapolis: University of Minnesota Press, 2014. xi +277 pp. with 8 color plates. $\$ 98$ hc; $\$ 28$ pbk

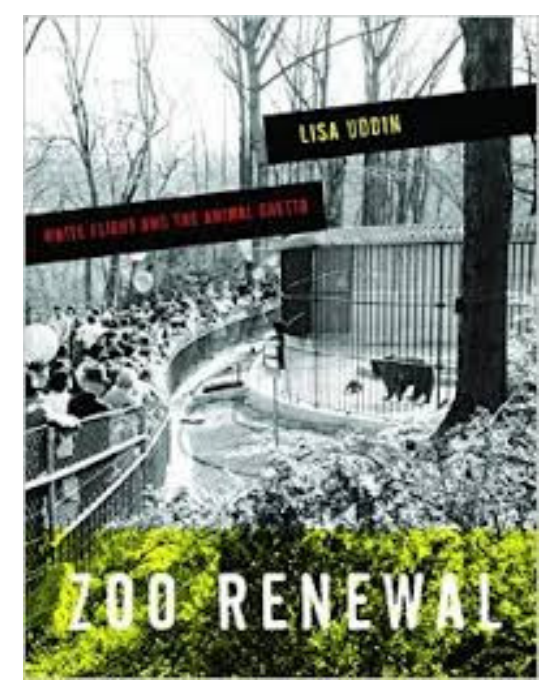

In May 2015, the Takasakiyama Zoological Park in southern Japan named a newborn Japanese macaque after Charlotte, a newborn British princess. The name was chosen after a public vote, reflecting the popularity of the British royal family and the cult of the cute ("kawaii") in Japanese consumer culture. Upon announcement of the name, however, complaints were lodged that it was disrespectful to the British monarch, and the zoo officials were urged to imagine how people in Japan might feel if a British zoo were to name a monkey after a Japanese princess. The Takasakiyama Zoo was about to revoke the name, when it was confirmed that the British royal family was not offended. Ironically, in January 2016, Charlotte became "Queen Monkey" of Takasakiyama, after the popularity vote dubbed "general election." Had she been named after the U.S. president, would the Japanese zoo have taken the same course as the Dresden Zoo in Germany several years ago to apologize for racial insensitivity and rename the primate? How would the Japanese public have reacted had Charlotte been a white thoroughbred or a Galapagos penguin? Answering these questions requires two things: an analytical frame of reference and coding schemes, and an understanding of contexts and circumstances in which zoos intersect with various realms of society. Combining both approaches, Lisa Uddin's Zoo Renewal: White Flight and the Animal Ghetto offers 
methodological insights that help us explore such crisscrossing human-animal boundaries and their racial connotations in the past and present.

The book provides a history of zoos and urbanism in mid-twentieth-century America. The 1960s and 1970s can be called "the Age of Reform" in the official institutional history of American zoos: within these two decades, many aspects of zoo environments were dramatically improved for the wellbeing of animals, offering them a naturalistic living space. Enchanted and educated, zoogoers came to realize their responsibility toward the natural environment. Challenging this whiggish narrative of zoo reform, Uddin presents a counter-analysis by disentangling racial undertones from contemporary commentaries on and spatial structure of reformed zoos. She argues that the euphoric lifestyle that renewed zoos presented to white, suburban zoogoers should be analyzed against the substandardized inner-city life of the nonwhite, which was associated with poverty, crimes, and riots, at a time of revolutionary change in urban geography and demography.

Zoo Renewal comprises an introduction, five chapters, and an afterword, along with eight color plates, each of which is adeptly organized to substantiate its thesis that "zoos have choreographed built and imagined environments of normative whiteness, crisscrossing species lines with startling agility" (228). Uddin begins with a question of why we feel bad at the zoo. While we are often disappointed to see its residents dull and motionless, watching them caged and exposed to inquisitive gazes makes us feel uneasy. The goal of the book is, however, not to prescribe remedies, but to unfold "the idioms and interactions through which feeling bad has been cultivated, amplified, relieved, and disavowed" (25). She claims that these idioms were racially loaded, as evident in the spatial interactions between zoo renewal and urban regeneration in the 1960s and 1970s. During this period of "white flight," middle-class Americans, by then consisting of various ethnic groups, were forced to reconfigure their racial and spatial identities. This acute concern underpinned the figurative re-creation of "whiteness" in zoos, as well as the presentation of particular animals as the embodiment of "white" hope. The book focuses on three institutes: the National Zoo in Washington, D.C., the San Diego Zoo, and the Wild Animal Park in San Diego County. As Uddin admits, it is unclear to what extent these three represent American zoos in general, but the book's in-depth analysis of the details and peculiarities of their spatial structure has established a baseline for that research that follows. 
Chapter One, "Shame and the Naked Cage," discusses the emerging criticism against the modernist style in the 1960s and 1970s. The term "the shame of the naked cage" (48) was used by Desmond Morris, zoologist and author of The Naked Ape (1967) and The Human Zoo (1969), to condemn wildlife captivity in modernist-style buildings, a famous example of which was London Zoo's Penguin Pool, constructed in 1934. Initially, modernist architecture was acclaimed for its aesthetic minimalism and transparency in which animals were expected to display their natural characteristics, but in the 1960s the virtue of simplicity turned into a feeling of shame about captive animals, who were exposed and vulnerable, without any hiding space or screen from the public gaze. Importantly, this feeling was directed not only at animal inmates but also to other human residents in the city. The examination of three selected individuals including Morris shows how the discourse of the naked cage "gained momentum by connecting zoo animals' condition of nakedness to the condition of other urbanities in the 1960s and 1970s, mirroring white middle-class shame over racial injustice in America cities" (29).

The second chapter, "Zoo Slum Clearance in Washington, D.C.," discusses the intersections between zoo renewal and urban regeneration by analyzing the revitalization of the National Zoo. As the postwar redevelopment highlighted the gaps between dark and black, and light and white aspects of life in the city, the rhetoric of a "zoological slum" gained such currency that the zoo was perceived as an ungovernable site, while slums were feared for their association with crimes and riots, and the imagined "animality" of black residents (74-90). The zoo's close association with urban slums evident in an accident on May 16, 1958, in which a white young girl, Julie Ann Vogt, was killed by a lion in the National Zoo. While other causalities of black children in the zoo hardly counted, this particular incident brought accusations against idle keepers, abnormal animals, and incautious visitors, and strengthened the call for zoo revitalization. Criticism of a "zoological slum" provided a platform for the Friends of the National Zoo to advocate pastoralism to renovate the zoo for white middle-class suburbanites. After twists and turns, the FOND's master plan for a pastoral zoo was transcended into the creation of an "urban sanctuary," which aimed to return the escaped citizens back to the city "with the experience of a tangible human-animal proximity"(97). In the 1960s, the innovations in zoo's architecture responded to the desire to reconstruct Washington as a "city in park"; for instance, the Great Flight Cage, monumental landmark aviary with grand vistas, was analogous to Dulles International Airport. By the 1970s, however, the monumental design had been replaced by the humanistic approach toward the re-creation of naturalistic environment. Regarding this

Humanimalia: a journal of human/animal interface studies

Volume 7, Number 2 (Spring 2016) 
change, Uddin argues that "the return to a gentler and greener architecture represented a form of soft white power" (116).

Considering the physical and metaphysical body of the white Bengal tiger Mohini, Chapter Three, "Mohini's Bodies," explores how this "white power" projected racial anxieties onto animal display. Initially, Mohini, meaning "enchantress" in the Hindi language, was esteemed for her exotic, noble Indian origin, but this public image was sexually charged. Contemporary commentaries employed a literary image of a harem courtyard, and in zoo photographs Mohini was transformed into an odalisque. This sensual imagery stemmed from the Orientalist conventions so much discussed by Edward Said, but Mohini the odalisque was not entirely functioning. In the ceremonial meeting with the tiger on the White House lawn, President Eisenhower looked disillusioned with her, as she declined to play an odalisque role and displayed her feline ferocity. In the 1970s, a new approach was taken to characterize Mohini as an ideal white mother. This shift of focus from exotic to domestic occurred amid increasing concerns with family fitness and health, which influenced "the reproductive choices and outcomes of men and women to maximize the 'quality' and demographic count of white American bodies of northern European descent" (142). In the postwar time, eugenic ideas lingered in American popular culture, underlying the idealization of whiteness of the white tiger, as Uddin notes: "By showcasing the breeding of its female white tiger as an attractive example of racial whiteness, the National Zoo became one instance of eugenics' continuity in a period of others" (143). This covert desire was only short-lived. After failed attempts to secure her lineage, Mohini could no longer remain "animal articulations of human whiteness"(155).

In Chapter Four, "White Open Spaces in San Diego County," the book turns from Washington, D.C. to San Diego and its two animal institutions. The identification of urban space as the site of poverty and violence, predominately inhabited by the black population, had as much influence over the San Diego Zoo as it had over the National Zoo. By the 1960s to 1970s, San Deigo had undergone a population explosion, and its suburbia developed north of the city, attracting many urban "refugees" from populated downtowns as well as from turbulent Los Angeles. Indeed, the fears of race riots came true in these two cities, while the temptations of a suburban lifestyle grew. These changes in popular sentiments reflected the revitalization of the San Diego Zoo; Uddin's analysis of Horn and Hoof Mesa, the zoo's largest multiunit exhibit, is particularly interesting. Horn and Hoof Mesa represented the ethos of suburbanism, characterized by ranch-style single-family houses, where middle-class whites could feel 
"togetherness" of their own family. Similarly, as far as media representation was concerned, Horn and Hoof Mesas showed a family of only one species such as parenting deer and their calves in their proximate "togetherness." Another interesting example is the theory of "flight distance," which states that animals should be given a certain physical distance from human observers or other species to feel safe and comfortable. Uddin suggests that this notion also responded to suburbanites' fears that other racial communities were stretching close to their residential area. The latter part of the chapter deals with the Wild Animal Park, constructed in San Pasqual Valley. The surrounding peaceful agricultural landscape endowed the neighborhood with the imagined pristine glory of the Anglo-American past. In this context, the exhibition of nonnative animals was as racially loaded as the revitalization of the San Diego Zoo. As Uddin summarizes:

Indeed, local energy and empathy for the plight of endangered species drew directly from the society's aesthetic power to renew a privileged history of unspoiled living and satisfy a white bourgeois desire for more personal space that was shared among different forms of suburban San Diego life. (190)

The racial elements also influenced the ways in which the Animal Wild Park represented a herd of white rhinoceros from South Africa. Chapter Five, "Looking Endangered," investigates how these African newcomers gained a public spotlight and were then enshrined as vulnerable objects of worship. Their arrival in 1971 responded to the transition of Africa's image from "Dark Continent" to the pristine fauna and flora (197). In this regard, Uddin argues, the white rhinos were presented to satisfy the public's yearning for intimacy with African wildlife, while concealing the historical backgrounds that made it once exploited and then worshiped. This argument has a historiographical significance: the postcolonial function of particular zoo animals as transforming the memory of past violence into the prospect of flourishing and nourishing offers a useful frame of reference, especially for a comparative analysis of zoos in different regions and time periods. For instance, the display of white rhinos can be compared with the wartime massacre of elephants in the Tokyo Imperial Zoo and their postwar celebrated exhibition in the same space, as discussed in Ian Miller's recent book. Uddin, meanwhile, discusses the implication of "whiteness" of the white rhinos. The Wild Animal Park tried to separate them from other less aesthetic rhinos and characterized their white body as proof of "just rhinos." This representation paved the way for identifying the whiteness of white people exclusively by lack of any physical and behavioral attribute, hence "just human."

Humanimalia: a journal of human/animal interface studies

Volume 7, Number 2 (Spring 2016) 
Lastly, Uddin revisits the debate over Woodland Park Zoo's hiring of Kenyan tour guides. The context of this debate was different from that from the 1970s, but there are some connections. I perceived that whether the Kenyan guides are associated with, or disassociated from, Africa's colonial past, and whether the image of "animality" is embedded therein, depends on the politics of collective memory - the politics of how to bridge the interpreted past to the imagined future. Zoo Renewal tells the history of American zoos no less than the contentious history in zoos, constituted by three entangled dichotomies: colonizing and colonized, human and nonhuman, and past and present.

The strength of this book is the consistency in argument that helps us orient ourselves in the studies and histories of American zoos, and we can learn how to use theory to gain deeper understanding of zoos in general. Nonetheless, the author's use of sources leaves some ambiguity about whether a material is descriptive or prescriptive, and whether a statement is metaphorical or not. In some places, the discourse analysis becomes unintentionally misleading, or at least confusing, as it is not always clear whether it intends to show (a) what happened, or (b) what contemporaries thought of what happened, or (c) what the author thinks contemporaries thought of what happened. For instance, while the contemporary zoologist Desmond Morris deployed the term "the shame of the naked cage" to criticize zoos, Uddin uses Morris's argument to discuss "Shame and the Naked Cage" (title of Chapter Two, italicized by the reviewer), thereby connecting "the shame over captive wildlife with the shame over those other city dwellers" (51). The evidence of this cross-referenced "shame" seems to be drawn largely from analogy, but it should be grounded in the sources concerning urban planners and dwellers in question. In this regard, I wished to hear the voices of those who actually lived in cities as well as their own readings of such racial fears and hopes as discussed in the book. When unnamed black boys died from falling into the creek in the National Zoo (76), how did their families and friends feel? Further, how did they respond when sentiments for reform were suddenly stirred up upon Julie's death? Displayed animals aside, how are these anonymous historical actors to be placed in Uddin's frame? The reception question is always a tricky one to answer, but it would remind us of the gaps remaining between their readings and our own.

Although I desired to know more about empirical aspects and individual perspectives, undoubtedly, Zoo Renewal makes an original, important contribution to the scholarship of zoo histories and human-animal studies as well as of the social and cultural history 
of urbanism, environmentalism and identity politics in twentieth-century America. It is highly recommended to those interested in these and related subjects.

\section{Works Cited}

Miller, Ian Jared. The Nature of the Beasts: Empire and Exhibition at the Tokyo Imperial Zoo. Berkeley: U of California P, 2013.

Said, Edward. Orientalism. New York: Pantheon, 1978. 